\title{
Investigation of Structural, Spectral, Optical and Thermal properties in Grown Pure Bis Thiourea Zinc Acetate (BTZA)
}

\author{
${ }^{1}$ Niji Abraham, ${ }^{2}$ Dr. V S John and ${ }^{3}$ Dr. P. Suja Prema Rajini \\ ${ }^{I}$ Research Scholar, Department of physics, Manonmaniam Sundaranar University, Tirunelveli, India. \\ ${ }^{2}$ Associate Professor \& Head, Department of physics, T.D.M.N.S College, T.Kallikulam, India. \\ ${ }^{3}$ Assistant Professor, Department of physics, T.D.M.N.S College, T.Kallikulam,
}

\begin{abstract}
The nonlinear optical single crystal of bisthiourea zinc acetate (BTZA) was grown successfully by slow evaporation technique using water as solvent at room temperature. The lattice parameters of the grown crystal were determined by X-ray diffraction studies. The quality of the grown crystal was examined by scanning electron microscopy (SEM).The optical transparency was determined by UV-visible and photoluminescence spectroscopy studies. The thermal behavior of the grown crystal was investigated by DTA and TGA analysis. The presence of functional group was studied using FTIR spectra. The second harmonic generation (SHG) of BTZA was confirmed the nonlinear property of the crystal by Kurtz powder technique.
\end{abstract}

Keywords: Crystal Growth, Second Harmonic Generation, FT-IR, TGA/DTA.

\section{Introduction}

Non linear optical (NLO) materials play an important role in the field of fiber optic communication, laser technology and optical signal processing. They are also used in the area of optoelectronics, telecommunication and optical storage device [1] due to their potential applications in emerging optoelectronic technologies $[2,3,4,5,6]$. Single crystals of the inorganic complex of thiourea have evoked much interest in the last few years due to their non linear optical properties $[7,8,9,10]$. Thiourea is an organic matrix modifier due to its large dipolmoment and its ability to form extensive network of hydrogen bonds [11]. The centrosymmetric thiourea molecule, when combined with inorganic salts yields non centrosymmetric complexes, which has nonlinear optical properties. Metal complexes of thiourea, commonly called semiorganics, include the advantages of both organic and inorganic part of the complex [12]. The structural and the optical, mechanical and thermal properties have been reported in detail in the literature (Jayalakshmi and Kumar 2006; Kannan et al 2004; Lydia Caroline and Vasudevan 2009; Thomas Joseph Prakash and Ruby Nirmala 2010). In this work, we discuss the synthesis and growth of BTZA single crystal and its structural, optical and thermal characterization.

\section{A. Crystal growth}

\section{Experimental Details}

BTZA salt was synthesized by using zinc acetate and thiourea in the stoichmetric ratio 1:2.The calculated amount of salt was dissolved in double distilled water and stirred well for 3 hours to yield a homogenious solution using magnetic stirrer. The purity of BTZA is achieved by successive recrystallisation. The solution was slightly heated up to an optimum temperature of $50^{\circ} \mathrm{c}$ to avoid decomposition of the solute molecules. The prepared solution was allowed to dry at room temperature and good optically transparent crystals were obtained by slow evaporation technique in a period of 25 days. The photograph of the crystal is shown in the figure 1.

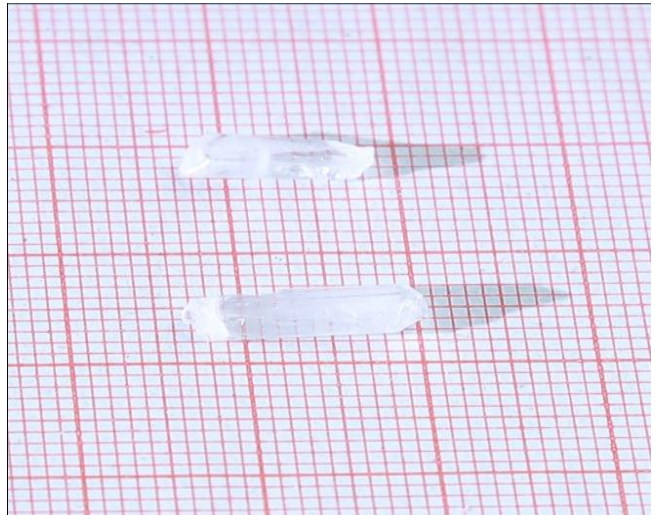

Fig. 1. Photograph of as grown BTZA single crystal 


\section{B. Single XRD}

\section{Results And Discussion}

Single XRD is a non destructive analytical technique which provides detailed information about the internal lattice of crystalline substances, including unit cell dimensions and bond length. Single crystal XRD studies were carried out using Bruker Kappa Apex II diffractometer. The single XRD analysis shows that the crystal belongs to monoclinic system with space group $\mathrm{P}_{21} / \mathrm{n}$. The unit cell dimensions are $\mathrm{a}=7.1270 \mathrm{~A}^{\circ}, \mathrm{b}=$ $17.7232 \mathrm{~A}^{\circ}, \mathrm{c}=11.1827 \mathrm{~A}^{\circ}, \alpha==90^{\circ}, \beta=103.096^{\circ}, \gamma=90^{\circ}$. The PLATON diagram of as grown BTZA single crystal is shown in figure 2.

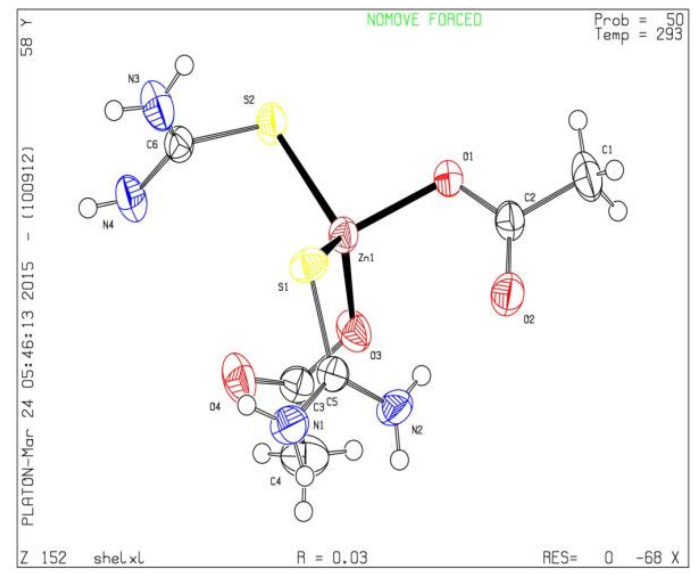

Fig. 2. The PLATON diagram of BTZA

Table 1. Crystallographic parameters

\begin{tabular}{|c|c|}
\hline Chemical formula & Zn (NH2CSNH2)2(CH3COO)2 \\
\hline Cell Parameters & $\mathrm{a}=7.1270 \mathrm{~A}^{\circ}$ \\
& $\mathrm{b}=17.7232 \mathrm{~A}^{\circ}$ \\
& $\mathrm{c}=11.1827 \mathrm{~A}^{\circ}$ \\
\hline Volume & $1375.79(12) \mathrm{A}^{3}$ \\
\hline Molecular Weight & 335.7 \\
\hline System & Monoclinic \\
\hline Space group & P21/n \\
\hline
\end{tabular}

\section{Powder XRD}

Powder XRD provides most definite structural information. The structural characteristics were done by $\mathrm{X}$-ray powder diffraction method, using Bruker D8 Advance X-ray diffractometer with $\mathrm{Cu}-\mathrm{K} \alpha$ radiation $(\lambda=1.5406 \AA$, X-ray tube voltage $=40 \mathrm{kV}$ and current $=35 \mathrm{~mA})$. The scan was taken in the $2 \theta$ range from 0 $80^{\circ}$ at increments of $0.02^{\circ}$ with a step time of $65.5 \mathrm{~s}$. The powder $\mathrm{x}$ ray diffraction results are shown in the figure 3.

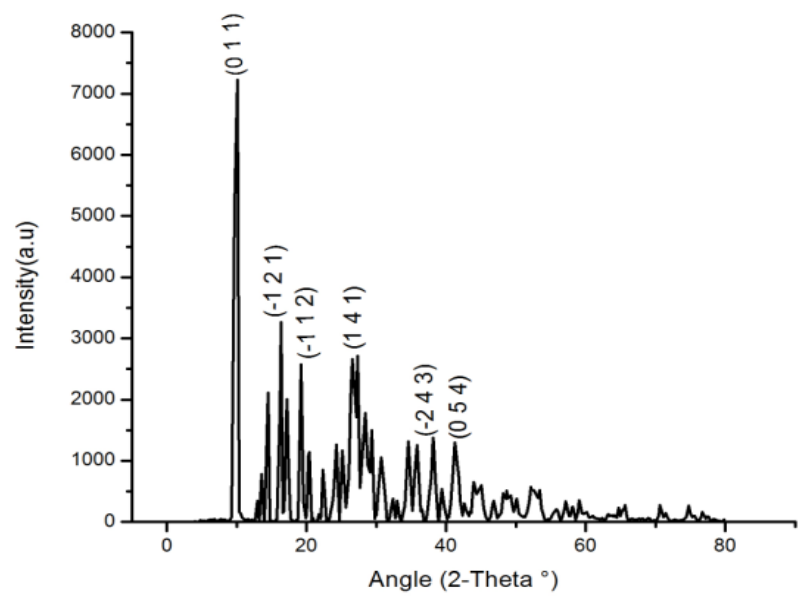

Fig. 3. Powder X-ray diffraction pattern of BTZA 


\section{Scanning electron microscopy}

The surface morphology of samples were analyzed with a scanning electron microscope JEOL MODEL JSM$6390 \mathrm{LV}$, operating at $20 \mathrm{kV}$. The SEM photographs are shown in figure 4. SEM images shows the pebble like structure of the crystal which is due to the surface roughness [21]
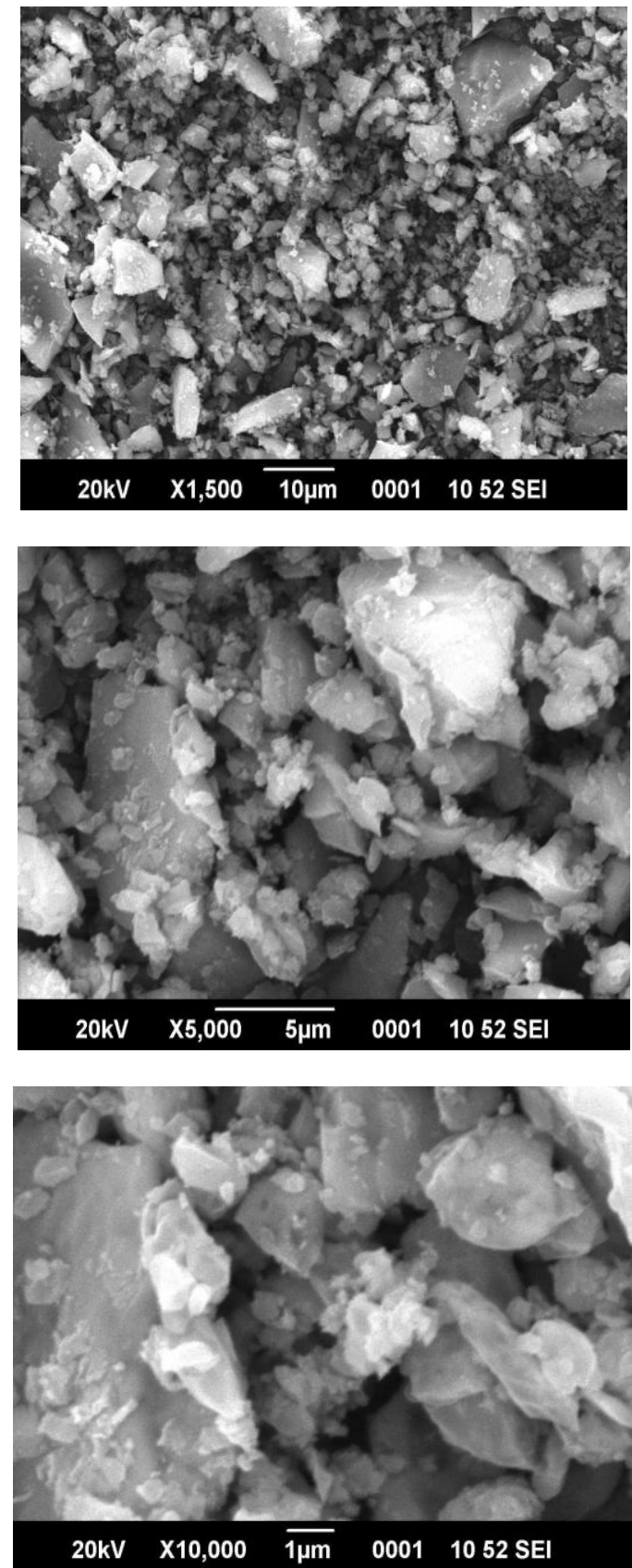

Fig. 4. SEM images of BTZA crystal

\section{E. $\quad U$ V-Vis Spectroscopy}

The optical absorbance was recorded from uv visible in the wavelength range of 200-1200 nm using UV-Visible spectrophotometer (Varian, Cary 5000). The thickness of the sample used for measurement was $2 \mathrm{~mm}$. The recorded spectra is shown in the figure 5 . The absorbance was reduced drastically between the wavelength of $360 \mathrm{~nm}$ and 1200nm offering wide transmission range. The wide range of transparency of grown crystal is an added advantage in the field of optoelectronic application [16]. 


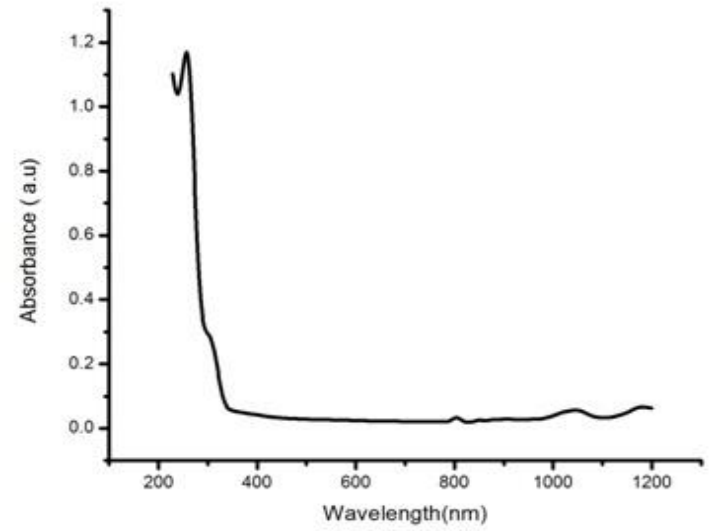

Fig. 5. UV-Vis spectrum of BTZA

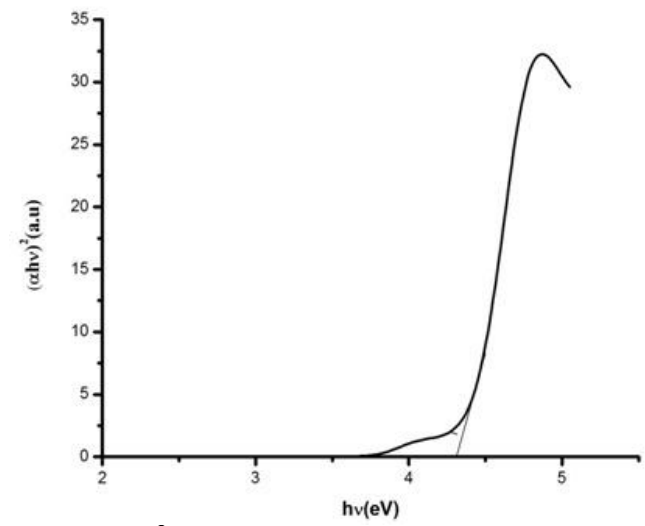

Fig. 6. $(\alpha h v)^{2}$ versus photon energy $(h v)$ of BTZA

The optical bandgap $\left(\mathrm{E}_{\mathrm{g}}\right)$ can be evaluated from the transmission spectra [13] using the relation $\alpha \mathrm{h} v=$ $\mathrm{A}(\mathrm{h} v-\mathrm{Eg})^{1 / 2}$, where $\mathrm{A}$ is a constant, $\mathrm{E}_{\mathrm{g}}$ the optical band gap , h the Planck's constant. The optical band gap of BTZA crystal is found to be $4.3 \mathrm{eV}$ and is shown in the figure 6 . The lower absorption and high optical band gap is most desirable for UV tunable laser materials [13].

\section{F. Photoluminescence Studies}

The photoluminescence (PL) spectrum of the sample was recorded by fluorescence spectrometer, Perkin ElmerLS 55, using an excitation wavelength of $275 \mathrm{~nm}$ is shown in the figure 7. The high energy violet emission was observed at $436 \mathrm{~nm}$ corresponding to an energy of $2.84 \mathrm{eV}$.

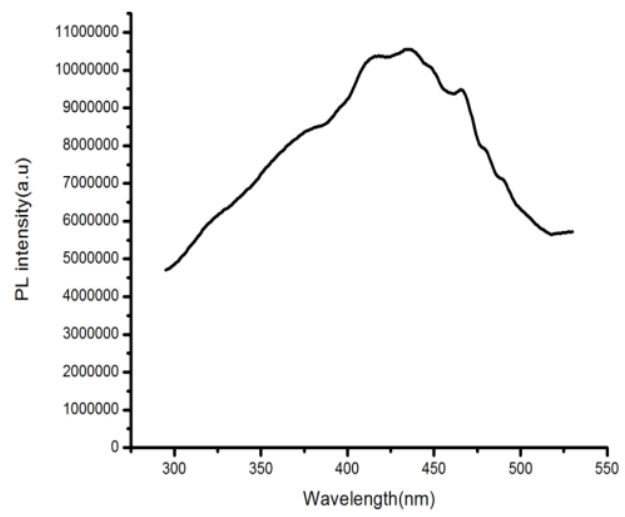

Fig. 7. Photoluminescence spectrum of BTZA

The two blue emissions were observed at $465 \mathrm{~nm}(2.66 \mathrm{eV})$ and $479 \mathrm{~nm}(2.58 \mathrm{eV})$ which is suitable for photonic device applications. Peaks in the visible region can be assigned to lattice related processes [23]. 


\section{G. Thermal studies}

Thermal behavior of the sample was analyzed by thermo gravimetric analyzer (TGA) and differential thermal analyzer (DTA) using Perkin Elmer STA 6000, heating from ambient to $700{ }^{\circ} \mathrm{C}$ at a rate $10{ }^{\circ} \mathrm{C} / \mathrm{min}$ is recorded and shown in the figure 8 . There is no weight loss below $150^{\circ} \mathrm{C}$ due to the absence of water in the crystal structure. The weight loss of about $57 \%$ takes place in the region $187^{\circ} \mathrm{C}$ to $280^{\circ} \mathrm{C}$. The weight loss may be due to decomposition of the compound and organic compound evaporation. In DTA curve there is an endothermic peak at $187.48^{\circ} \mathrm{C}$, which is the melting point of the specimen. No decomposition up to the melting point ensures the suitability of the material for the application in lasers where the crystals are required to withstand high temperature. The analysis also shows that BTZA is thermally stable up to $150^{\circ} \mathrm{C}$; hence it is suitable for NLO applications.

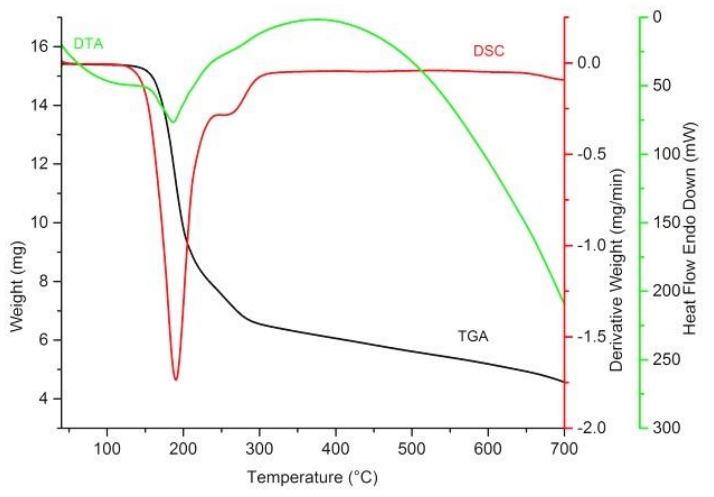

Fig. 8. TG/DTA/DSC curves of BTZA

\section{H. NLO studies}

The non linear optical property of the grown crystal was determined using Kurtz and Perry method. A high intensity Q-switched mode locked Nd-YAG laser was used to generate about $1.13 \mathrm{~mJ} / \mathrm{pulse}$ at the $1064 \mathrm{~nm}$ fundamental radiation. The input laser beam with pulse duration $10 \mathrm{~ns}$ and frequency repetition $10 \mathrm{~Hz}$ is passed through the micro crystalline powdered sample packed in a capillary tube. The efficiency of the sample was compared with the micro crystalline powder of KDP as the reference material. The bride green emission (532 $\mathrm{nm}$ ) from the specimen was collected a photomultiplier tube and finally measured on the storage oscilloscope (CRO) as output voltage. The output from the SHG test confirms the non linear nature of the crystal.

\section{I. $\quad$ FTIR}

Fourier transform infrared (FTIR) spectra of the samples were recorded by FTIR spectrophotometer (Thermo Nicolet, Avatar 370) in the range 4000 to $400 \mathrm{~cm}^{-1}$ by $\mathrm{KBr}$ pellet technique [22]. The recorded FT-IR spectra of undoped BTZA is provided in figure 9.

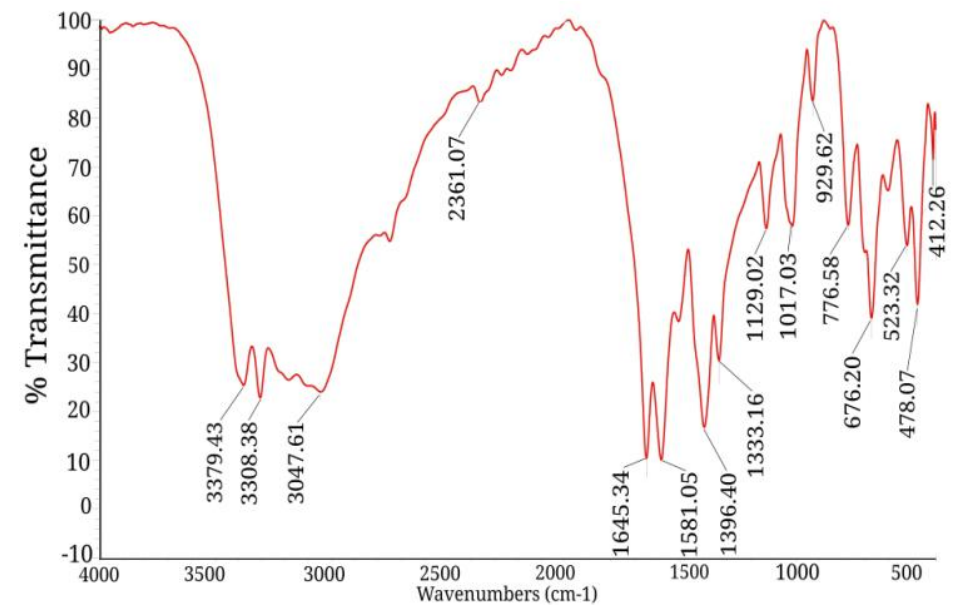

Fig. 9. FT-IR spectrum of BTZA crystal 
In BTZA, Zinc can coordinate with thiourea in two possible ways that is through nitrogen or through sulphur of thiourea [14]. The high frequency $\mathrm{N}-\mathrm{H}$ absorption bands in the region $3100-3400 \mathrm{~cm}^{-1}$ in the spectrum of thiourea were not shifted to lower frequencies on the formation of metal thiourea complex indicating that nitrogen to zinc bonds are absent and that bonding must be between sulphur and zinc atoms [15]. The S-C-N bending vibrations at $494 \mathrm{~cm}^{-1}$ of thiourea shifted to lower frequency $478 \mathrm{~cm}^{-1}$. The symmetric and asymmetric $\mathrm{C}=\mathrm{S}$ stretching vibrations at 730 and $1417 \mathrm{~cm}^{-1}$ of thiourea are shifted to low frequency region at 676 and $1396 \mathrm{~cm}^{-1}$ in BTZA respectively which confirms the formation of metal sulphur coordination bond [19]. $\mathrm{C}=\mathrm{S}$ stretching vibration at $1089 \mathrm{~cm}^{-1}$ is shifted to higher frequency $1129 \mathrm{~cm}^{-1}$. This shows that binding of zinc with thiourea is through sulphur [20]. It can be seen from Table 2 .

Table 2. FTIR Data Comparison of BTZA with thiourea

\begin{tabular}{|c|c|c|}
\hline Thiourea(cm-1) & BTZA $\left(\mathrm{cm}^{-1}\right)$ & Assignment \\
\hline 494 & 478 & S-C-N symmetric bending \\
\hline 730 & 676 & $\mathrm{C}=\mathrm{S}$ symmetric stretching \\
\hline 1089 & 1129 & $\mathrm{C}=\mathrm{S}$ asymmetric stretching \\
\hline 1417 & 1396 & $\mathrm{C}=\mathrm{S}$ asymmetric stretching \\
\hline 1627 & 1645 & $\mathrm{NH}_{2}$ bending \\
\hline
\end{tabular}

The observed bands of BTZA with their vibrational assignments have been tabulated in Table 3 along with the reported values of BTZA for comparison.

Table 3. Single crystal data of pure BTZA crystals

\begin{tabular}{|c|c|c|}
\hline BTZA cm $^{-1}($ reported[ 17]) & BTZA cm $^{-1}$ & Assignment \\
\hline 487 & 478 & S-C-N symmetric bending \\
\hline 777 & 776 & $\mathrm{C}=\mathrm{S}$ symmetric stretching \\
\hline 1135 & 1129 & $\mathrm{C}=\mathrm{S}$ symmetric stretching \\
\hline 1403 & 1396 & $\mathrm{C}=\mathrm{S}$ asymmetric stretching \\
\hline 1582 & 1581 & $\mathrm{NH}_{2}$ bending \\
\hline 3375 & 3379 & $\mathrm{NH}_{2}$ stretching \\
\hline
\end{tabular}

\section{Conclusion}

Good quality single crystal of BTZA was grown by slow evaporation technique under room temperature. Grown crystals were characterized by XRD and confirmed that the crystal belongs to monoclinic system with space group $\mathrm{P}_{21} / \mathrm{n}$. Optical transmission study confirms the quality of the crystals for NLO application. The optical band gap was found to be $4.3 \mathrm{eV}$. The photoluminescence studies confirms the quality of the crystals for photonic device applications. TGA and DTA analysis has revealed that BTZA is stable up to $150^{\circ} \mathrm{C}$, after that it undergoes a physical transformation associated with mass changes. The functional groups were verified using FTIR analysis. SHG conversion efficiency makes the crystal a latent material for NLO application.

\section{Acknowledgements}

The authors thank the authorities of Sophisticated Test and Instrumentation Centre (STIC) in the Cochin University of Science and Technology, Kochi for providing instrumental facility for characterization. The authors are also grateful to Prof P.K Das, IISC Bangalore for extending the facilities to measure SHG efficiency.

\section{References}

[1]. Prasad P. N and Williams D. J., Introduction to Nonlinear Optical Effects in Molecules and polymers, Wiley Interscience, New York, 1991.

[2]. Iwai M, Kobayashi T, Furya H, Mori Y and Sasaki T, Jpn.J.Appl.Phys., 36(1997)1.276.

[3]. Ledoux L synth, Metal 54(1993)123.

[4]. Marey H.O, Warren L.F, Webb M.S, Ebbers C.A, Velsko S.P, Kennedy G.C and Catella G.C, Applied Opts.31 (1992)5051

[5]. Wang X.Q, Xu D, Yuan D.R, Tian Y.P, Yu W.T, Sun S.Y, Yang Z.H, Fang Q, Lu M.K, Yan Y.X, Meng F.Q, Guo S.Y, Zhang G.H and Jiang M.H, Mater.Res.Bull.34 (199), 2003.

[6]. Yuan D.R, Xu D, Zhang N, Liu M.G and Jiang Chin M.H, Phys.Lett.13 (1996)841.

[7]. M.H.Jiang, D.Xu, G.C Xing and Z.S shao, Synth.Cryst 3-4 (1985) 1.

[8]. W.B.Hou, M. H Jiang, D.R.Yuan, D.R.Yuan, D.Xu, N.Zhang, M.G.Liu, and X.T.Tau, Mater.Res.Bull.28 (1993) 645.

[9]. S.G.Bhat and S.M.Dharmaprakash, J.Cryst.Growth 81(1997) 390.

[10]. W.B .Hou, D.Xu, D.R.Yuan and M.G.Liu, Cryst.Res.Technol.29 (1994)939.

[11]. K. H Hellwege and A. M Hellwedge(Eds), Landolt - Bornstein Database. Diamagnetic Molecules. Group II- 14a. Molecules and Radicals,Springer-Verlag(1982), pp.584.

[12]. S,Annie Roshan,C. Joseph and M.A Ittachen, Mater.Lett.49,299(2001).

[13]. Vivek P and Murugakoothan P. Opt Laser Technol 2013;49:288-95.

[14]. Swaminathan K, Irving H.M.N.H and Inorg J, Nucl. Chem.26 (1964)1291.

[15]. Nakamoto K, IR Spectra of Inorganic and Co-ordination Compounds. IIEd, Wiley, New York, 1978.

[16]. Bairava Ganesh R, Kannan V, Sathyalakshmi R and Ramasamy P., Mater. Lett. 61(2007) 706. 
Investigation of Structural, Spectral, Optical and Thermal properties in Grown Pure Bis Thiourea ..

[17]. $\quad$ Lydia Caroline M and Vasudevan S, Current applied physics. 9 (2009)1054.

[18]. Kannan V, Rajesh N.P, Bairava Ganesh R, Ramasamy P, J.Cryst.Growth 269(2004)565.

[19]. Swaminathan K, Irving H.M.N.H and Inorg J, Nucl. Chem. 26(1964)1291.

[20]. Ushasree P.M, Jayavel R,Subramainian C and Ramasamy P, J.Cryst.Growth 197(1999)216.

[21]. Ruby Nirmala L,Thomas Joseph Prakash J, Spectrochimica Acta part A:Molecular and Biomolecular spectroscopy 110(2013) 249254

[22]. D. Jayalakshmi, and J. Kumar, Cryst. Res. Technol. 41, No. 1, 37- 40 (2006).

[23]. Arun. k.j, Division for research in advanced materials, Ph.D., Thesis, Draft, (2009), Cochin University of Science and Technology. 